\title{
МЕТОД СЕМАНТИЧЕСКОГО ОПИСАНИЯ ТЕРМИНОВ КАК АКТУАЛЬНЫЙ СПОСОБ РАЗВИТИЯ НАУЧНОЙ РЕЧИ ЛИНГВИСТОВ-ПЕРЕВОДЧИКОВ
}

\section{METHOD OF SEMANTIC DESCRIPTION OF TERMS AS AN ACTUAL WAY TO DEVELOP SCIENTIFIC SPEECH OF LINGUISTS-TRANSLATORS}

\section{T. Makarova}

Summary: The article highlights the vital problem of building the language of scientific communication and its usage in communication and translation. It examines methodological approaches to the development of the syntax of scientific speech in the bachelor's degree of translation specialties in the new information environment. The article analyzes the factors that hinder the correct semantic definition of terms and their entry into active speech. The empirical material of the study reflects the state of linguistic competence of students-linguists. A practical method of working out the linguistic description of terms is proposed, which allows students to combine their ideas about the term with its true meaning.

Keywords: competence, cognition, scientific speech, translation, teaching method, definition, term.
$\mathrm{H}$ есмотря на совершенствование компьютерной лингвистики и повсеместное распространение онлайновых машинных словарей, профессия переводчика продолжает в XXІом веке занимать устойчивые позиции на рынке труда. Многие федеральные ВУЗы осуществляют профессиональную подготовку кадров в этой области по направлению «Лингвистика» профиля «Перевод и переводоведение», как в рамках академического бакалавриата, так и магистратуры. В сложной международной обстановке ограничения передвижений и самоизоляции в период пандемии, перевод продолжал реализовываться через новые облачные платформы event-сопровождения, которые активно заявили о себе на рынке сервисных услуг. Можно с уверенностью утверждать, что востребованность профессии переводчика сохранилась, а следовательно не потерял своей значимости вопрос профессиональных компетенций переводчика. Не вызывает сомнения, что для осуществления как последовательного (consecutive translation), так и синхронного перевода (simultaneous translation) с русского языка на английский требуется совокупность знаний и навыков, в частности, владение грамматикой и синтаксисом иностранного языка, переключаемость, хорошее произношение, знание стилистических норм. Вместе с тем, классики отечественного переводоведе-

\author{
Макарова Татьяна Генриховна \\ К.и.н., дочент, Российский экономический университет \\ имени Г.В. Плеханова (г. Москва) \\ fortunatat@mail.ru
}

Аннотация: B статье исследуется актуальная проблема формирования языка научного общения и его применения в коммуникации и переводе. Рассматриваются методические подходы к развитию синтаксиса научной речи в бакалавриате переводческих специальностей в условиях новой информационной среды. Анализируются факторы, сдерживающие корректное семантическое определение терминов и их выход в активную речь. Эмпирический материал исследования отражает состояние языковой компетенции студентов-лингвистов. Предлагается практическая методика отработки лингвистического описания терминов, позволяющая соединить представления студентов о термине с его подлинной семантикой.

Ключевые слова: компетенция, познание, научная речь, перевод, метод обучения, дефиниция, термин.

ния неоднократно подчеркивали сложность процесса перевода, при котором единицы перевода на исходном языке должны быть эквивалентно переданы на переводящем языке.

Понимание смысла высказывания и возможность его передачи на другом языке - до конца не познанное явление. Многие исследователи перевода посвятили свои труды рассмотрению особой природы этого феномена. Развивая стройную систему переводческих трансформаций, Я.И. Рецкер считал, что в процессе перевода переводчику не столь важно сопоставить отдельные грамматические формы, сколь выявить «структурносемантические узлы», составляющие единое понятийное целое [4, с.10]. Известный исследователь перевода В.Н. Комиссаров пытался настойчиво проникнуть в глубинные истоки перевода, исследовать когнитивное понимание оригинала и факторы, влияющие на его воссоздание на другом языке. Он полагал, что процесс понимания оригинала и формирования передаваемой мысли в переводе носит неодноразовый характер; сначала переводчик уясняет содержание оригинала, подыскивает вариант его передачи, потом вновь возвращается к оригиналу, уточняет свое понимание. При этом он подчеркивал значение лингвистической компе- 
тенции, справедливо утверждая, что адекватная передача содержания в переводе возможна лишь средствами развитого языка [1, с.92-93]. В монографии «Как стать переводчиком?» автор научных работ по теории перевода К.Р. Миньяр-Белоручев, говоря о процессе перевода, выдвигает утверждение об объективном наличии двух способов перевода: смыслового и знакового. Поскольку знаковый способ легко приводит на практике к буквализмам, и текст перевода может принять уродливую форму «смеси французского с нижегородским», то, по его мнению, очевидны преимущества смыслового способа: «осознав смысл произнесенной фразы, переводчик формулирует его на другом языке» [2, с.135]. В научных концепциях речепорождения прошлого века прослеживается стремление объяснить сложный путь, который проходит говорящий от замысла к высказыванию, в категориях языкознания. Выделяется иерархия языковых уровней, в грамматике говорящего определяются синтаксические модели, которые привязываются к конкретной коммуникативной ситуации [3, с.208-209]. В XXI-ом веке в механизмы речевой деятельности стремительно вторгаются психо и нейролингвистика. В области перевода его качество и эффективность, столь необходимые в рыночных условиях, прочно увязываются с пониманием фразы (meanings) и осознанным воплощением этого понимания в речь через корректный выбор переводчиком тех или иных языковых средств.

Передача смыслового инварианта была и остается одной из самых трудных проблем для многих переводчиков в связи с неуловимостью смысла, его многоликостью и контекстуальной обусловленностью. Недопонимание смысла при восприятии текста приводит к искажениям и иным недочетам при переводе. Ошибки же в речепроизводстве могут неправильно репрезентовать социальную действительность, так как язык имеет свойство отражать сущность бытия. Поэтому изучение проблемы того, как соотносятся процессы вычленения смысла слова/фразы с выбором языкового эквивалента и синтаксическим конструированием высказывания следует признать весьма актуальным. С этих позиций целесообразно обратиться к использованию возможностей, которые предоставляет дефиниция - определение термина, позволяющее через описание субьектно-предикатных отношений раскрыть значение слова/фразы. Методологической базой познания в данном случае служит герменевтика как наука об интерпретации текстов, понимании предмета, принципах его расшифровки и теории значений. С дидактических позиций дефиниция позволяет стимулировать мыслительный процесс и может рассматриваться как обучающий метод в процессе образовательного взаимодействия и организации учебно-познавательной деятельности учащихся. Создание полноценной выразительной дефиниции, раскрывающей содержание (смысл) имени посредством описания существенных и отличительных признаков предметов и явлений, обозначаемых данным именем (денотата имени), активизирует такие когнитивные категории, как мышление, представление, воображение, а ее соотнесение с эталонной дефиницией, закрепленной в современной лексикографии, позволяет развить точность, чистоту и богатство научной речи. В предписании Совета Европы CEFR (Common European Framework of Reference - Европейская система уровней владения иностранным языком), систематическое изучение дистрибутивных и семантических характеристик слова в родном и изучаемом языках отнесено к эффективному способу развития словарного запаса учащихся [7]. Навыки точной передачи смысла фразы находят широкое применение в переводе: это и переводческий комментарий, перевод реалий, безэквивалентной лексики. Они способствуют преодолению лингвистически «проблемных» ситуаций, помогут справиться с креативной задачей создания переводческой интерпретации образных фразеологизмов (фразеологические сочетания с «затуманенным» смыслом).

Структура методической единицы: «слово/фраза перевод - описание, в виде субъективного представления учащегося, выполненное на русском и английском языке - словарная дефиниция - ее перевод на английский язык» содержит необходимые элементы развертывания речи, а соотнесение выбора номинаций учащихся с эталонной дефиницией отражает степень приближения к смыслу и нормам лексической сочетаемости. Возьмем для примера слово «концепция» - перевод "concept" - студенты считают, что это «идея - idea» - словарная дефиниция: «система взглядов на явления в мире, в природе и обществе» - английский вариант: "The system of views on phenomena in the world, in nature and society". Налицо развертывание структуры речевой фразы и расширение ее научных границ. Следует помнить, что терминологический пласт специальных текстов не исчерпывается однокомпонентными терминами, изобилует многокомпонентными терминами и терминологическими рядами. В качестве примера двухкомпонентного термина воспользуемся словосочетанием «гражданский мир» - перевод: "civil peace" - описание, данное учащимися: «спокойствие населения, объединение людей одной проблемой» - словарная дефиниция: «мир между политическими силами внутри одного государства, который охватывает значительную часть населения»; английский вариант: "peace between political forces within one state, which covers a significant part of the population". Дефиниция содержит элементы научной репрезентации картины мира в корреляции с соответствующими языковыми средствами. Рассмотрим вариант трехкомпонентной коллокации: «Реальные доходы населения» - в переводе "Real (disposable) income of the population" - учащиеся считают, что это «подсчет заработка населения». Словарная дефиниция: «Это количество свободных денег, которое остается у человека после выплаты всех налогов и обязательных платежей»; английский вариант дефини- 
ции: "Real amount of free money that a person has left after paying all mandatory payments" содержит важное лексическое дополнение в виде слов "налоги» "taxes" и обязательные платежи "mandatory payments". Терминологические ряды могут включать в себя четырех- и более компонентные словосочетания, что приводит к усложнению их семантико-синтаксической структуры, например «Приоритетные направления внутреннего туризма» - Priority directions of domestic tourism или «Основной закон Российской Федерации» - Basic law of the Russian Federation. В большинстве случаев существует возможность вывести общее значение термина из значений его компонентов, однако в отдельных случаях перевод затруднен, когда семантические границы терминологического ряда размыты. Например, в терминологическом ряде «математическое описание психологических феноменов» компоненты словосочетания представляют собой «внутренне связанную систему разнонаправленных отражений элементов действительности» [6]. При подборе переводческого эквивалента в этих случаях может потребоваться дополнительный этимологический анализ компонентов, установление происхождения слов, порядка их следования и значений, учет контекста. Следует также отметить, что увеличение числа компонентов в составе термина снижает шансы переводчика на успешный поиск переводного эквивалента в словарях.

Для выявления текущего состояния языковой компетенции лингвистов-переводчиков и их способности представить картину мира лексикой научного описания и перевода автором было осуществлено прикладное лингвистическое исследование. Студентам третьего года обучения (средний возраст 20 лет, количество 100 человек, направление подготовки «Перевод и переводоведение»), предлагалось создать «авторские» описания заранее заданных терминов и выполнить их перевод на иностранный язык. В качестве терминологической основы был взят корпус общественной и экономической лексики, прозвучавшей в декабре 2020 года в выступлении Президента РФ В.В. Путина перед населением России (всего 57 лингвистических единиц, извлеченных методом сплошной выборки) [5]. Установка на социальное проектирование реальности, столь очевидная в ответах Президента на вопросы граждан, позволила очертить необходимое и достаточное функционально-терминологическое поле исследования. Принимая во внимание повторяемость базовых терминов в СМИ, можно предположить, что они когнитивно должны были быть знакомы данной возрастной группе. Исходя из предлагаемого метода семантического описания, перед участниками опроса была поставлена задача выявить смысл терминов и дать его самостоятельное описание с упором на выражение главных признаков предмета, существенных для перевода. Термины были выстроены в лингвистической иерархии по восходящей: однокомпонентные, двух-, трех-, и четырехкомпонентные.
В качестве дефидентов (определяемых понятий) первого уровня выступали однословные термины (общей численностью 25) : Социум - Society, Community / Стагнация - Stagnation / Деструкция - Destruction / Компромисс - Compromise / Цивилизация - Civilization / Суверенитет - Sovereignty / Иерархия - Hierarchy / Генезис - Genesis / Синдром - Syndrome / Реставрация - Restoration / Boлатильность -Volatility / Модернизация - Modernization / Эйфория - Euphoria / Ответственность - Responsibility / Концепция - The concept / Гипотеза - Hypothesis / Доминирование - Dominance / Категория - Category / Модератор - Moderator / Экспертиза -Expertise / Легитимность - Legitimacy / Инфраструктура - Infrastructure / Референдум - Referendum. Анализ представленных описаний свидетельствует о том, что задание было выполнено довольно успешно: процент явных определений составил $80 \%$, что означает, что большинству студентов удалось прямо указать присущие предмету признаки, добиться приемлемой эксплицитной формы изложения и найти переводческий эквивалент. Процент неявных определений составил соответственно 20\%. В этих случаях указывались синонимы или применялась имплицитная форма изложения, не имеющая вида равенства, совпадения двух понятий. Тем не менее, у трети опрошенных возникли сложности с описанием общефилософских терминов, таких как «генезис», «концепция», «цивилизация». Так, учащиеся были уверены, что генезис связан с происхождением геологических образований, а цивилизация представляет собой поселение людей. $60 \%$ респондентов не знали значения слова «волатильность». В лингвистических средствах описания предиката и его перевода хотелось бы видеть более богатое языковое наполнение. Имели место отдельные ошибочные способы определения по кругу, когда дефиниция определялась через дефидент (напр. синдром это совокупность синдромов).

На втором этапе дефидентами выступали устойчивые коллокации из 2х слов (всего 15), представляющие устойчивые словосочетания-клише: Социальное государство - The welfare state / Общественное сознание - The public consciousness / Социальная сфера - Social sphere / Меры противодействия - Counteraction measures / Социальные сети - Social networks / Общественное благо - The public good / Черта бедности - The poverty line / Амбициозная цель - The ambitious goal / Национальные проекты - National projects. На третьей стадии определялись коллокации из трех слов: Система государственного управления - Public administration system / Отечественные лекарственные препараты - Domestic medicines / Первичная система здравоохранения - Primary health care system / Общенациональная избирательная кампания - National election campaign / Полярные точки зрения - Polar points of view / Традиционные политические партии - Traditional political parties / Перспективы развития отношений - Prospects for the development of relations / Обнуление президентских сроков - Zeroing 
out presidential terms. Подсчет результатов показал, что число явных дефиниций, в которых определяемый предмет находится в отношениях тождества с определением, снизилось на 10 процентов и составило 70 процентов. Соответственно, 30 процентов пришлось на дефиниции, не имеющие четко выраженной структуры (неявные). Две трети респондентов не сумели определить, что такое «геополитические интересы», «политические пристрастия», «стратегические перспективы», «первичная система здравоохранения», «традиционные политические партии». Ошибочными были признаны дефиниции, где отсутствовал главный признак предмета, например, определяя «реальные доходы населения» студент не сообщал о вычете налогов. Выявленные недочеты отразились на качестве интерпретации понятия на иностранном языке.

Придание некоего фиксированного смысла многокомпонентным языковым выражениям из четырех слов и их описание оказалось самой сложной задачей. Процент справившихся с заданием снизился до 50ти. Половина опрошенных сообщили, что смогли сделать перевод, однако испытывали сложности с определением, что такое «Демографическая ситуация в каждом регионе» - Demographic situation in each region, «Снижение конкурентоспособности германской экономики» Declining competitiveness of the German economy и «Высокий уровень политического сознания» - High level of political consciousness. Камнем преткновения стал также МРОТ (минимальный размер оплаты труда), который определялся как наименьшая сумма выплат работнику без указания на то, что эта методика применяется в качестве базовой для расчета всех социальных пособий. Данное словосочетание актуализировалось в связи с введением в России с 1го января 2021 новой методики подсчета МРОТ. Студенты испытывали затруднения при установления суммарного смысла высказывания как некоего целого, тем самым размывалась основа для правильного речевого действия. Усложнившаяся синтаксическая организация терминологического ряда не позволила многим раскрыть его содержание на ино- странном языке. Вместе с тем, многие студенты отметили, что по мере выполнения задания улучшалась логика научного мышления. Практически все опрошенные сообщили о своих дальнейших действиях по поиску непонятых ими слов в словаре и уяснению для себя их значений, что свидетельствует о высокой педагогической эффективности данного метода. Проведенное исследование состояния речевой компетенции показывает, что в целом студенты готовы к речевым действиям в пределах известных им границ обучения. Вместе с тем, усложнение синтаксической структуры высказывания существенно затрудняет понимание ими его смысла, что может негативно отразиться в будущем на его переводе на иностранный язык.

Таким образом, современным условиям быстро меняющейся информационной среды соответствуют изменения в смыслах и общей сочетаемости употребляемой лексики. Развитие познавательной активности в этой области через собственную информационную деятельность учащихся следует признать недостаточным для формирования профессиональных компетенций лингвистов-переводчиков. Создание дефиниций путем раскрытия содержания новых понятий является эффективной формой нового знания о слове, позволяет преодолеть искажения семантики, буквализмы и стилистические неточности в переводе. Представленный метод семантического описания терминов направлен на улучшение языковой компетенции и развивает навыки самостоятельного продуцирования научного стиля речи. Он же и весьма пластичен, может быть трансформирован в упражнения на построение высказывания, ситуативные упражнения, упражнения на норму стиля и использоваться при изучении студентами старших курсов продвинутого уровня "Advanced" любого специального или художественного текста. Метод апробирован в 2020г. в практике преподавания дисциплин «Теория специального перевода», «Теория последовательного и синхронного перевода» на отделении «Лингвистика» в Российском экономическом университете имени Г. В. Плеханова.

\section{ЛИТЕРАТУРА}

1. Комиссаров В.Н. Переводческие исследования. Избранные статьи 1968-2005. М.: «Р. Валент», 2020. 160 с.

2. Миньяр-Белоручев Р.К. Как стать переводчиком? М.: Изд-во «Готика», 1999. 176 с.

3. Норман Б.Ю. Грамматика говорящего: От замысла к высказыванию. Изд.3-е. М.: «ЛЕНАНД», 2018. 232 с.

4. Рецкер Я.И. Теория перевода и переводческая практика. 4-е изд., стереотип. М.: «Р. Валент», 2010. 244 с.

5. Ежегодная пресс-конференция В.В. Путина. [Электронный ресурс]. URL: http://kremlin.ru/events/president/news/64671 (дата обращения 20.12.2020)

6. Лексическое значение слова. [Электронный ресурс]. URL: https://ru.wikipedia.org/wiki/ (дата обращения 10.01.2021)

7. Common European Framework of Reference for Languages: Learning, Teaching, Assessment. Cambridge. 2002. [Электронный ресурс]. URL: https://rm.coe.int/1680459f97 (дата обращения 15.01.2021) 